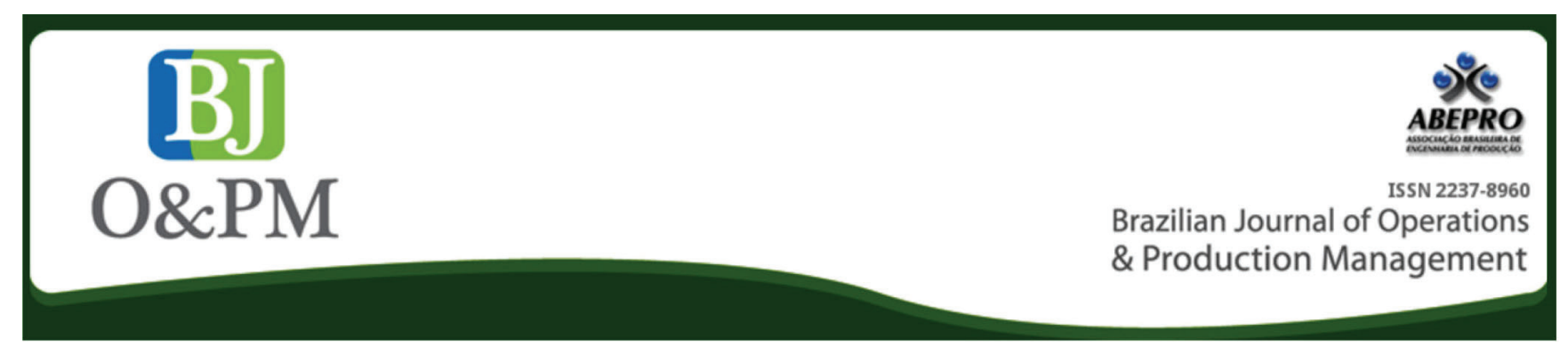

\title{
THE INTERNET OF THINGS SENSORS TECHNOLOGIES AND THEIR APPLICATIONS FOR COMPLEX ENGINEERING PROJECTS: A DIGITAL CONSTRUCTION SITE FRAMEWORK
}

\author{
Hamilton Lopes de Miranda Junior ${ }^{1}$, Nelson Roberto Albuquerque de Bezerra², \\ Marlene Jesus Soares Bezerra ${ }^{1}$, José Rodrigues de Farias Filho ${ }^{1}$ \\ 1 Anhanguera University Center \\ 2 Foundation for Support to Technical School - FAETEC \\ 3 West Zone State University Center - UEZO \\ 4 Fluminense Federal University - UFF
}

\begin{abstract}
Purpose: The paper aims to present constructs related to Internet of Things, which are expected to be integrated to, and improve the implantation phase of Complex Engineering Projects. The traditional implantation methods for Complex Engineering Projects are neither effective nor efficient to deal with the massive data generated by their productive processes. It usually causes high levels of rework, schedule delays and financial losses. Design/methodology: In this paper a systematic literature review on loT architecture, sensor technologies and possible applications was presented. These constructs were identified and selected from a lexical analysis of a reseach basis carried out with NVivo software. Findings: We have been in the emerging $4^{\text {th }}$ Industrial Revolution and the Internet of Things (IOT) has a valuable role to make an easier way to success for Complex Project implementations. Therefore, a correlation scheme of the constructs and their applications identified in the bibliography was proposed. Originality/value: A concept and a framework for a "Digital Construction Site" (DCS) from the application of loT Sensors (IOTS) in the shipbuilding industry. It is valuable for readers who want to understand alternatives to improve the results of typical processes on implementation phase of Complex Engineering Projects, with open source technologies.
\end{abstract}

Keywords: IoT; Internet of Things; Sensors; Digital Construction Site. 


\section{INTRODUCTION}

In the past decade, much research has focused on Complex Projects, their productiveness and performance. This study is focused on the implementation phase of Complex Engineering Projects up to the $4^{\text {th }}$ Industrial Revolution, era of emerging Internet of Things (IoT), Big Data, Cloud Computing, Wireless Sensor Networks (WSN), and Radio Frequency Identification (Wang et al., 2016).

It is unclear how to minimize the delays in scheduling, the high rework rates and the financial losses in Complex Projects; meanwhile, there are many technological resources and tools to make things easier and faster and provide more reliable results in terms of industrial processes, such as fabrication and assemblying routines. With technological advances in industrial schemes, the concept of smart industry or Industrie 4.0, which is a concept with flexible and agile production oriented by Cyber-Physical Systems (CPS) and IoT, has emerged (Wan et al., 2014).

IoT has been playing an essential role ever since it appeared, since it consists of net-worked embedded devices that communicate by means of wired or wireless networks or internet to create ubiquitous - the presence everywhere context awareness and information-based applications (Jing et al., 2014). Frequently, these devices interact with the physical world ubiquitously, consisting of wired sensors, Radio Frequency Identifications (RFIDs), Wireless Sensor Networks (WSNs), and mobile devices (Atzori et al., 2010; Tan et Wang, 2010; Parwekar, 2011).

There is a common sense that all things may be controlled or monitored, may be identified automatically by other things, may communicate with each other through the internet, and may even make decisions by themselves (Tsai et al., 2014). Therefore, the findings of this study show that it is not reasonable to continue to use standard procedures to make decisions through the Big Data.

Era, without counting on IoT, which is a concept that has become a reality, consists in a set of available resources and tools to be applied, improving the results on the integration of embedded computing devices, smart objects, people, and physical environments that are typically linked by a communication infrastructure.

One of the reasons for the bad performance on the implantation of Complex Projects is the failure on integrating demands with data collection of productive processes to facilitate decisions making. How to organize the data has been a primary challenge for data professionals, due to the diversity and complexity (Balazinska et al., 2007; Cooper et James, 2009; Navarro et al., 2011; Fan et Chen, 2010).
Sethi et Sarangi (2017) cite the two most popular definitions for loT: the first is "the interaction between the physical and digital worlds" (Vermesan et al., 2011) and the second is "the paradigm in which computing and networking capabilities are embedded in all kinds of objects" (Peña-López, 2005). IoT devices are equipped with embedded sensors, actuators, processors and transceivers. The interaction with the physical environment is made by sensors and actuators. Sensors are devices that provide inputs about their internal state or environment while actuators are devices used to effect a change in the environment, such as a temperature controller. The present Review is based on bibliometrics, statistical and quantitative technique for measuring the rates of production and dissemination of scientific knowledge.

The purpose of this paper is to present and explore constructs related to Internet of Things as the Internet of Things Sensors (IoTS) which are expected to be integrated to and its contribution to improve the results of Complex Engineering Projects, using a base from a systematic literature review.

The contribution of this paper includes 3 parts: the first part is the proposal for a systematic review of IoT; the second part is the discussion about possible architectures' and sensors' technology; the third part is the outline of IoTS applications and the presentation of a scheme relatiing IoT applications and technologies to digitalize the Construction Site. It is valuable for readers who want to understand how to improve results of typical processes on the implementation phase of Complex Engineering Projects, with open source technologies.

In Section 2, we present the method used in literature review. In Section 3, the main loT architectures are surveyed. In Section 4, IoT technologies are discussed as Sensors, Data Mining, and Cloud Computing. In Section 5, a scheme for loT applications and technologies on the shipbuilding industry is proposed. In Section 6, a conclusion is presented.

\section{REVIEW METHOD}

The present literature review was based on the application of Boolean logic method, bibliometrics, statistical and quantitative technique to map and select papers for the references research basis. This research began with the reading of the article "Robots in shipbuilding industry", which served as an inspiration for preparing a keywords tree (see Figure 1) and the followed Boolean logic: (industr* AND cloud* AND "big data" AND (RFID OR IOT OR computing OR robotic OR shipbuilding), refined by "relevance", "revised per pair", "articles", since 2012, "English", returning 1,706 scientific papers on searching at "Periodicos Capes" website. Then the titles and abstracts were analysed, considering their alignment with research context, reducing the articles sample to 
92. All articles with indexed Impact Factor JCR (Journal Citation Report) were kept in a research basis, resulting in 63 papers. It is worth mentioning this proposal in such a dynamic and iterative process, where each step must be revised, aiming for better research basis.

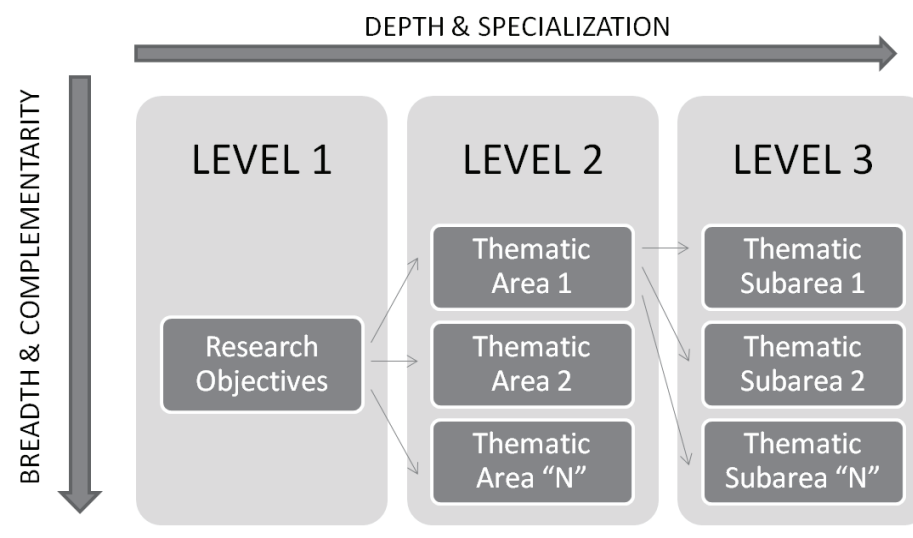

Figure 1. Keywords Tree

Source: Farias Filho (2012)

The connectors "AND" and "OR" were used in the Boolean logic search. This means that the keywords within the same thematic area are connected by "OR", and those from different thematic areas are connected by "AND", since it is desired to find articles from these thematic areas, simultaneously.

The selected articles were uploaded into the NVivo software so that the lexical analysis of the contents of those articles could evidence constructs for the development of the present article, as well as for the construction of the framework of the Digital Construction Site. In this way, we obtained from the lexical analysis of the research base, the IoT architecture and the IOT technologies, which are the constructs to be discussed below.

\section{IOT ARCHITECTURES}

Some architectures of loT have been studied by different academics. These researchers have explored paradigms as Social IoT (SloT) which considers social relationships between objects or devices that count on many interoperating components, such as: ID, Metainformation, Security Controls, Service Discovery, Relationship Management, and Service Composition. All of these modules are aimed to provide integrated services to users (Sethi et Sarangi, 2017; Atzori et al., 2011).

On reflecting on the main concept of the loT, the most basic architecture has three layers: perception, network and application. The first layer has sensors for gathering information on environment. The second layer connects smartthings devices and servers. The third layer delivers application services to users (Mashal et al., 2015; Wu et al., 2010).

The other known architecture is the five-layer architecture, which includes perception, transport, processing, application and business layers. The role of the perception and application layers has the same function as the architecture with three layers. The transport layer transfers the sensor data between the layers perception and processing. The processing layer, known as the middleware layer, includes technologies, such as Big Data processing, Cloud Computing and databases. It stores, analyzes and processes data that comes from the transport layer. The business layer manages the loT system, its applications, business and privacy modules (Mashal et al., 2015; Wu et al., 2010).

Sethi et Sarangi (2017) discuss about two other system architectures, cloud and fog computing. The cloud architecture is such a cloud centric structure in which the applications are above it and the smart things are below it (Gubbi et al., 2013). The fog architecture consists of six layers: transport, security, storage, preprocessing, monitoring and physical layer where the sensors and gateways do the analytics and data processing partially (Aazamand et Huh, 2014).

\section{IOT TECHNOLOGIES}

An loT technologies classification based on architectural layers is presented by Sethi et Sarangi (2017), (see Figure 2). The present paper was focused on Sensors (Perception layer) and Applications.

\subsection{Sensors}

The sensor technology is essential for awareness atributes of all IoT applications. By means of such technology it is possible to collect data from the environment and the different kinds of sensors are: Mobile Phone Based Sensors (MPBS), Medical Sensors, Neural Sensors, Environmental Sensors, Chemical Sensors, Radio Frequency Identification (RFID) and Actuators (Schmidt et Laerhoven, 2001). The storage and processing of data can be done in the network itself or in a remote server. All data preprocessing is mainly done by either the sensor or some other kind of device. The storage and processing capabilities are constrained by factors as limitations of size, energy and protocol standards (Sethi et Sarangi, 2017).

Mobile Phone Based Sensors (MPBS) usually have a sort of embedded sensor and it increases the possibilities of building smart loT solutions with MPBS (Khan et al., 2013). 


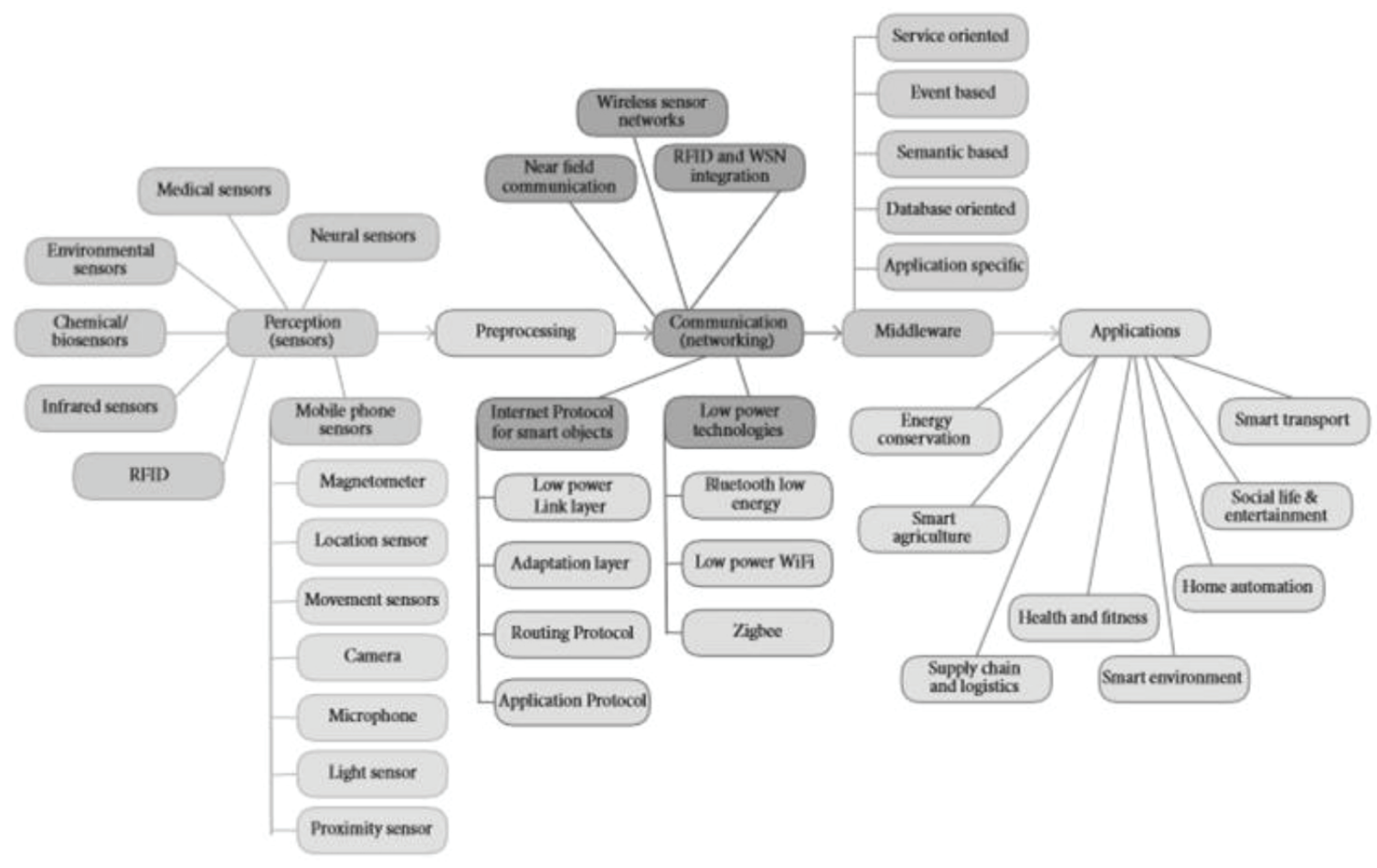

Figure 2. loT technologies

Source: (Farias Filho, 2012)

Some of these sensors are: accelerometer, gyroscope, camera, microphone, GPS (Global Positioning System), light sensor, magnetometer, barometer, thermometer and humidity sensor (Sethi et Sarangi, 2017).

Medical Sensors are used to measure and monitor medical parameters in the human body (Bui et Zorzi, 2011). Studies describe in detail the different wearable sensing devices (McGrath et Scanaill, 2013) and relate their applications to the monitoring of medical parameters, such as the heart rate, pulse, blood pressure, body temperature, respiration rate and blood glucose levels (Pantelopoulos et Bourbakis, 2010). These wearables include smart watches, wristbands and smart textiles. Another new loT device is the monitoring patch, a rubbery structure with embedded components that is attached to the skin. These patches are stretchable and disposable, they are supposed to be worn for a few days to monitor the vital signs of the person's health continuously (Swan, 2012).

Neural Sensors are part of the technology used for reading brain signals, also called EEG (Electroencephalography). By the brain computer interface, it is possible to understand neural signals in the brain, which infer the state of the brain, train it for better attention towards things, manage stress and has a better mental well-being. The neurons inside the brain communicate electronically and create an electric field, which can be sensed in real time, thereby being measured from outside by its frequencies, this is known as neurofeedback (Gruzelier, 2014).
Environmental Sensors are applied to measure parameters, such as pressure, humidity, temperature, gas presence or another particulate in water or air (Sekhar et al., 2010).

Chemical Sensors are used to sense chemicals or biochemicals on the basis of taste and odor of food (Bhattacharyya et Bandhopadhyay, 2010), in smart environments, consisting a transducer and an advanced pattern recognition software (Manna et al., 2014).

A sensor based identification technology - the Radio Frequency Identification (RFID) - has two basic devices, the RFID tag and RFID reader. The RFID tag is a chip with an embedded antenna, capable of storing data and may be of two kinds: active (has power source) or passive (its power source is the eletromagnetic field of the RFID reader) (Want, 2006). The data stored in the RFID tag is transmitted via radio waves and captured by the RFID reader, reaching a range up to hundreds of meters for communication between the RFID devices (Zhu et al., 2012).

Completing the sensors functionality, the actuators are devices that might effect a change in the environment by converting electrical energy into some useful energy. The actuators, which induce motion, can be classified into: electrical actuators (by the use of the electrical energy), hydraulic actuators (by the use of fluid power or hidraulic power) and pneumatic actuators (by the use of the pressure of compressed air) (Sethi et Sarangi, 2017). 
In order to make loT smarter, collecting and handling with all the data from the environment and sensors, lots of analysis technologies are introduced into IoT; one of the most valuable technologies is data mining (Chen et al., 2015).

\subsection{Data mining}

On the basis of the definition of data mining and its functions, a typical data mining process includes the following steps (see Figure 3).

a) Data preparation: prepares the data for mining. It includes 3 substeps: integrating data in various data sources and cleaning the noise of the data; extracting some parts of data into the data mining system; preprocessing the data to facilitate data mining.

b) Data mining: apply algorithms to the data to find the patterns and evaluate patterns of discovered knowledge.

c) Data presentation: visualize the data and represent mined knowledge to the user (Jiawei et Kamber, 2011).

Data mining functionalities (Chen et al., 2015) include classification, clustering, association analysis, time series analysis, and outlier analysis. Classification is important for managing decision making. The goal of classification is to accurately predict the target class for each case in the data (Kesavaraj et Sukumaran, 2013). Clustering algorithms divide data into meaningful groups so that patterns in the same group are similar in some sense and patterns (Jain et Dubes, 1988). Association analysis targets the discovery of rules, showing attribute value associations that occur frequently and help in the generation of qualitative knowledge, which, in turn, helps in decision making (Gosain et Bhugra, 2013). A time series is a collection of temporal data objects, such as large data size, high dimensionality, and continuous updating (Fu, 2011). Outlier detection refers to the problem of finding patterns in data that are very different from the rest of the data, based on appropriate metrics (Gogoi et al., 2011).
Silva et al. (2013) proposed big data mining system for IoT, focusing on the integration with devices and data mining technologies supported by cloud computing loT.

\subsection{Cloud computing}

Six years ago, there was no consensus oriented to the definition of cloud computing (Rong et al., 2011). Nowadays, infrastructure, Platform, and Software as a Service (IaaS, PaaS, and SaaS) are the main cloud computing approaches, which are results of Service Oriented Architecture (SOA) (Laukkarinen et al., 2013). Currently "embedded", IoT, or sensor cloud proposals utilize loT devices only as heterogeneous data providers and use existing cloud computing approaches for homogenizing and further refining the data for the end-user applications (Parwekar, 2011; Alamri et al., 2013). Cloud computing provides virtualized computing services without logical or location relation to physical hardware (Armbrust et al., 2010), in the literature, cloud computing is defined as "offering hardware and software resources as services across a parallel and distributed system, consisting of a collection of interconnected and virtualized computers that are dynamically provisioned" (Tsai, 2009; Nezhad et al., 2009).

Wang (2014) classifies the cloud services into four categories: Infrastructure as a service (laaS) - main services include the provision of virtual hardware, network, storage, computing power, and so forth; Software as a service (SaaS) - a "software on demand" that refers to application systems that can be activated directly on the internet; Platform as a service (PaaS) - delivers an integrated service oriented platform for the whole process in the software development (i.e. design, test, execution, and deployment); Database as a service (DaaS) moves the traditional database features, including the definition of data and the storage and retrieving of data, over to the network.

Studies (Kurschl et Beer, 2009) highlight that cloud computing has an important role in terms of wireless sensors networks architecture, since they are limited in their processing power, battery life, and communication speed, while cloud computing, on the other hand, has powerful compu-

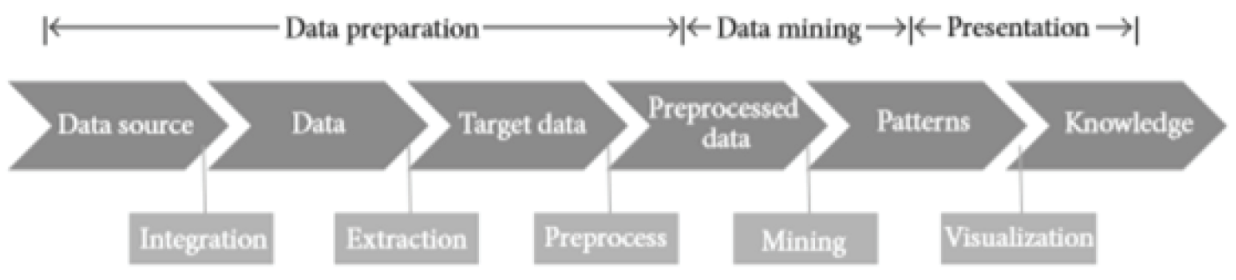

Figure 3. The data mining overview Source: Chen et al. (2015) 
tational and processing capacity and the communication speed is much faster as well. Researches have established that cloud computing and wireless-sensor network together may provide the most reliable, scalable, dynamic, and composable resources for IoT applications (Gubbi et al., 2012; Kortuem et al., 2010; Vermesan et al., 2011), including the complex engineering projects, such as those developed for the shipbuilding industry.

\section{DIGITAL CONSTRUCTION SITE}

The shipping industry is a basic industry that plays an important role in the international trade and logistics around the world on transporting raw material and energy. According to the International Maritime Organization (IMO) (2008), over $90 \%$ of the global trade volume, carried by sea and maritime transport, was regarded as a dominant mode of transport. With the globalization of production, shipping has impacted the global supply chain management significantly, as it is evidenced by the world's total container ship dead-weight tonnage (Yang et al., 2013). For the reasons above the shipbuilding industry was selected to be explored as a scenario for IoT applications. The main processes of shipbuilding consist of working stages including designing, cutting/forming, block assembling, pre-outfitting/painting, pre-erection, erection and quay (see Figure 4).
The manufacturing processes to be competitive depend on the organisational strategies, technology and the integration level in the high-tech industry's value chain (Alvarez et Marin, 2013). In this context, the IoT capabilities, such as cooperation, communication, identification, sensing, actuation, localization, embedded information processing, and user interfaces (Mattern et Floerkemeier, 2010) are feasible by sensor devices that collect data and send data to data center. Therefore, communication and identification are the two major functions of a Wireless Sensor Network (Terada, 2009), which is expected to be a key technology for various IoT applications, such as home automation and energy saving (ZigBee Alliance, 2007a and 2007b).

The loT applications cover buildings and facilities of smart environments, and smart industrial plants (Gluhak et al., 2011; Libelium, 2013). Similarly, IoT solutions can be applied within of a smart construction site, or "smart shipyard". Notwithstanding, a scheme to represent the constructs, IoT applications and IoT Sensors technologies, related to a typical Construction Site and the interactions with themselves, is proposed (see Figure 5).

The use of loT sensors in industrial environments is what characterizes a green industry as well as a smart industry (Wang, 2014). Bringing together the concepts of "green" and "smart" facilities, and focusing on the implementation phase of an enterprise, more specifically in the construction sites, the "digital construction site" can be conceptualized.

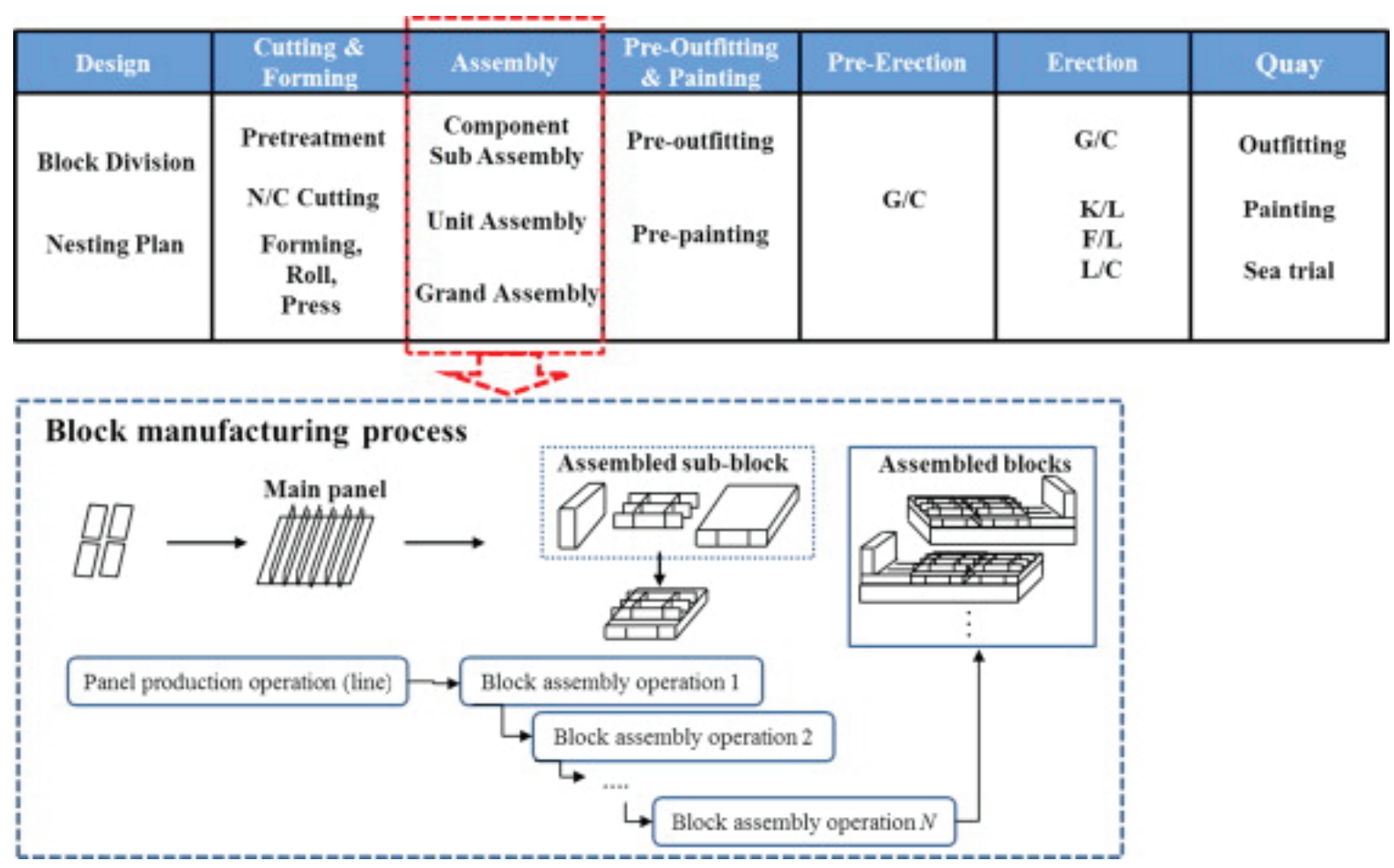

Figure 4. Processes for shipbuilding and block manufacturing Source: Parka et al. (2014) 


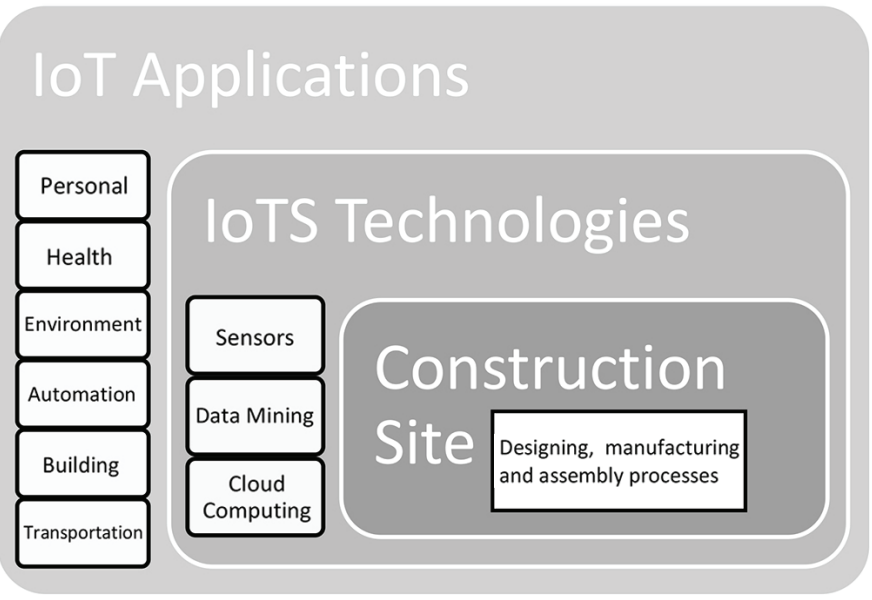

Figure 5. "Digital Construction Site" Framework Source: The authors' own.

In this way, a DCS is the facility where the activities of the implantation of an enterprise takes place, in which loT sensors are used in specific applications, aiming at the environmental sustainability, guarantee of operations safety, well-being of employees, besides safeguarding the productivity, quality and profitability of production systems and processes.

\section{ANALYSIS AND DISCUSSION OF RESULTS}

In this section the analysis and the discussion of the results that served to answer the research question "how to improve the results of the typical processes in the implementation phase of the Complex Engineering Projects with open source technologies" are carried out.

Based on loTS technologies and some of their possible applications in the shipbuilding industry, the following examples can be pointed out for each application:

- Personal: Sensors with the support of cloud computing and data mining can be used to monitor and quantify quickly and accurately the entry and location of employees in construction sites.

- Health: it is possible to verify the reduction of hours lost in the absence to the work and the decrease in the number of trips to the doctor due to health problems through controls of the vital signs of the worker, such as temperature and blood pressure control through the use of skin pads and RFID system.

- Enviromental: The quantitative and qualitative controls of the emission of gases, the consumption of electric energy and compressed air can be carried out by loTS, which allows greater economy, in ad- dition to comply with legal environmental requirements.

- Automation: The quality of some of the welding processes can be significantly improved with their respective automation and robotization. Such improvements are based on the use of loTS for the positioning of parts and activation and shutdown of welding equipment.

- Building: The use of tagging technology in tracking and locating equipment, such as cranes, trucks, and other vehicles or mobile equipment for assembling subsystems can improve resource utilization and reduce task execution times at the construction site.

- Transportation: The shipment, transportation, storage, distribution and application processes of parts and systems are better fulfilled and monitored with the support of loTS technologies. The loss rates of parts and rework are significantly reduced, in addition to improving the space management of the site with the use of loTS.

The above does not contemplate all possible loTS applications in construction sites; however, it aims to justify and answer the research question.

\section{CONCLUSIONS}

The concept and the realization of the "Internet of Things" make the world ubiquitous since the loT embraces every physical object into the network. The combination of the Internet, the cloud services, embedded sensors, and data mining techs will enable the transformation of all objects into smart objects for attending industrial demands with high complexity.

The digital construction site (DCS) is based on the sustainability of production to cope with the global challenges. Although the implementation of DCS has been facing challenges, the existing technologies must be used and technical innovations most be promoted simultaneously. With the existing technologies, some application demonstrations have already been built. Therefore, the Industrie 4.0 and the digital construction site are able to be implemented in a progressive way, along with the developing technologies.

This paper summarized the perspective of the loT from three correlative technical aspects: architectures, technologies and applications. It presented a correlation with technologies, applications and the DCS. It is hoped that this survey has been useful to researchers and practitioners in complex projects, helping them to understand the IoT and 
motivate more efforts to develop solutions for issues in order to promote the progress of the loT.

This study was limited by using a qualitative method for selecting the constructs. Based on current research, future studies on specific applications on construction and assembly industry and the presention of a visionary scenario for the Digital Construction Site are proposed. The quantitative methods shall be applied in the future study.

\section{Conflict of interests}

The authors declare that there is no conflict of interests regarding the publication of this paper.

\section{Acknowledgements}

The authors are researcher's members of the nucleus for studies in complex projects, at the Fluminense Federal University.

\section{REFERENCES}

Aazamand, M.; Huh E. N. (2014), "Fog computing and smart gateway based communication for cloud of things", In Proceedings of the 2nd IEEE International Conference on Future Internet of Things and Cloud (FiCloud'14), pp.464-470, Barcelona, Spain, Aug. 2014.

Alamri, A. et al. (2013), "A survey on sensor-cloud: architecture, applications, and approaches", International Journal of Distributed Sensor Networks, vol. 2013, Article ID 917923, 18 pages.

Alvarez, I.; Marin, R. (2013), "FDI and Technology as Levering Factors of Competitiveness in Developing Countries", Journal of International Management, Vol. 19, No. 3, pp. 232-246.

Armbrust, M. et al. (2010), "A view of cloud computing", Communications of the ACM, Vol. 53, No.4, pp.50-58.

Atzori, L. et al. (2010), "The internet of things: a survey", Computer Networks, Vol. 54, No. 15, pp. 2787-2805.

Atzori, L. et al. (2011), "SloT: giving a social structure to the internet of things", IEEE Communications Letters, Vol. 15, No. 11, pp.1193-1195.

Balazinska, M. et al. (2007), "Data management in the worldwide sensor web," IEEE Pervasive Computing, Vol. 6, No. 2, pp. 30-40.

Bhattacharyya, N.; Bandhopadhyay, R. (2010), "Electronic nose and electronic tongue," in Nondestructive Evaluation of Food Quality, pp. 73-100, Springer, Berlin, Germany.
Bui, N.; Zorzi M. (2011), “Health care applications: a solution based on the internet of things," in Proceedings of the 4th International Symposium on Applied Sciences in Biomedical and Communication Technologies (ISABEL'11), ACM, Barcelona, Spain, Oct. 2011.

Chen, F. et al. (2015), "Data Mining for the Internet of Things: Literature Review and Challenges", International Journal of Distributed Sensor Networks, Vol. 2015, Article ID 431047, 14 pages.

Cooper J.; James A. (2009), "Challenges for database management in the internet of things," IETETechnical Review, Vol. 26, No. 5, pp.320-329.

Fan, T.; Chen, Y. (2010), "A scheme of data management in the internet of things," in Proceedings of the 2nd IEEE International Conference on Network Infrastructure and Digital Content (ICNIDC'10), pp.110-114, Sep. 2010.

Farias Filho, J. R. (2012), "Theoretical Essay on Bibliographical Research in Strategic Management", UFF/TEP, Niteroi, RJ. Handout of Strategic Management - Mastering Program in Production Engineering.

Fu, T. C. (2011), "A review on time series data mining", Engineering Applications of Artificial Intelligence, Vol. 24, No. 1, pp. 164-181.

Gluhak, A. et al. (2011), "A survey on facilities for experimental internet of things research," IEEE Communications Magazine, Vol. 49, No. 11, pp.58-67.

Gogoi, P. et al. (2011), "A survey of outlier detection methods in network anomaly identification," The Computer Journal, Vol. 54, No. 4, pp. 570- 588.

Gosain, A.; Bhugra M. (2013), "A comprehensive survey of association rules on quantitative data in data mining," in Proceedings of the IEEE Conference on Information \& Communication Technologies (ICT '13), pp. 1003-1008, JeJu Island, Republic of Korea, Apr. 2013.

Gruzelier, J. H. (2014), “EEG-neurofeedback for optimising performance.l: are view of cognitive and affective outcome in healthy participants," Neuroscience and Biobehavioral Reviews, Vol. 44, pp.124-141.

Gubbi, J. et al. (2012), "Internet of Things (IoT): A Vision, Architectural Elements, and Future Directions," FGCS, available at: http://www.cloudbus.org/papers/Internetof-Things-Vision-Future2012.pdf (Accessed on April 2012).

Gubbi, J. et al. (2013), "Internet of Things (IoT): a vision, architectural elements, and future directions," Future Generation Computer Systems, Vol. 29, No. 7, pp. 1645-1660.

International Maritime Organisation - IMO (2008), International Shipping and World Trade: Facts and Figures, pp. 1-29.

Jain, A. K.; Dubes, R. C. (1988), "Algorithms for Clustering Data", Prentice Hall, Englewood Cliffs, NJ, USA. 
Jiawei, H.; Kamber, M. (2011), “Data Mining: Concepts and Techniques", Morgan Kaufmann.

Jing Q. et al. (2014), "Security of the internet of things: perspectives and challenges", Wireless Networks, Vol. 20, No. 8, pp. 2481-2501.

Kesavaraj, G.; Sukumaran, S. (2013), “A study on classification techniques in data mining," in Proceedings of the 4th International Conference on Computing, Communications and Networking Technologies (ICCCNT'13), pp.1-7, Jul. 2013.

Khan, W. Z. et al. (2013), "Mobile phone sensing systems: a survey," IEEE Communications Surveys \& Tutorials, Vol. 15, No. 1, pp.402-427.

Kortuem, G. et al. (2010), "Smart objects as building blocks for the internet of things," IEEE Internet Computing, Vol. 14, No. 1, pp.44-51.

Kurschl, W.; Beer, W. (2009), "Combining cloud computing and wireless sensor networks," in Proceedings of the 11th International Conference on Information Integration and Web-based Applications \& Services (iiWAS'09), pp. 512-518.

Laukkarinen, T. et al. (2013), “An Embedded Cloud Design for Internet-of-Things", Hindawi Publishing Corporation, International Journal of Distributed Sensor Networks, Vol. 2013, Article ID 790130, 13 pp.

Libelium (2013), "50 Sensor Applications for a Smarter World,", http://www.libelium.com/top 50 iot sensorapplicationsranking (Accessed on August 2007).

Manna, S. et al. (2014), "Vehicular pollution monitoring using IoT", in International Conference on Recent Advances and Innovations in Engineering, ICRAIE 2014, ind, May 2014.

Mashal, I. et al. (2015), "Choices for interaction with things on Internet and underlying issues," Ad Hoc Networks, Vol. 28, pp. 68-90.

Mattern, F.; Floerkemeier, C. (2010), "From the internet of computers to the internet of things", in From Active Data Management to Event-Based Systems and More, K. Sachs, I. Petrov, and P. Guerrero, Eds., vol.6462 of Lecture Notes in Computer Science, pp.242-259, Buchmann Festschrift.

McGrath, M. J.; Scanaill, C. N. (2013), "Body-worn, ambient, and consumer sensing for health applications," in Sensor Technologies, pp. 181-216, Springer.

Navarro, M. et al. (2011), "An integrated network and data management system for heterogeneous WSNs", in Proceedings of 8th IEEE International Conference on Mobile Adhoc and Sensor Systems (MASS'11), pp. 819-824, Valencia, Spain, October 2011.

Nezhad, H. R. et al. (2009), "Virtual business operating environment in the cloud: conceptual architecture and challenges", LectureNotesin ComputerScience, Vol. 5829, pp. 501-514.
Pantelopoulos, A.; Bourbakis, N. G. (2010), "A survey on wearable sensor-based systems for health monitoring and prognosis," IEEE Transactions on Systems, Man and Cybernetics Part C: Applications and Reviews, Vol. 40, No. 1, pp.1-12.

Parka, J. et al. (2014), "An integrated approach for ship block manufacturing process performance evaluation: Case from a Korean shipbuilding company", International Journal of Production Economics, Vol. 156, pp. 214-222.

Parwekar, P. (2011), "From internet of things towards cloud of things," in Proceedings of the 2nd International Conference on Computer and Communication Technology (ICCCT'11), pp. 329-333, Sep. 2011.

Peña-López, I. (2005), Itu Internet Report 2005: The Internet of Things, ITU, Switzerland.

Rong, X. H. et al. (2011), "A large-scale device collaboration mechanism", Journal of Computer Research and Development, Vol. 48, No. 9, pp. 1589-1596.

Schmidt, A.; van Laerhoven, K. (2001), "How to build smart appliances?" IEEE Personal Communications, Vol. 8, No. 4, pp. 66-71.

Sekhar, P. K. et al. (2010), "Chemical sensors for environmental monitoring and homeland security", The Electrochemical Society Interface, Vol. 19, No. 4, pp. 35-40.

Sethi, P.; Sarangi, S. R. (2017), "Internet of Things: Architectures, Protocols, and Applications," Journal of Electrical and Computer Engineering, Vol. 2017, Article ID 9324035, 25 pp.

Silva, W. M. et al. (2013), "Smart cities software architectures: a survey," in Proceedings of the 28th Annual ACM Symposium on Applied Computing (SAC'13), pp. 1722-1727, Mar 2013.

Swan, M. (2012), "Sensor mania! The internet of things, wearable computing, objectivemetrics, andthequantifiedself2.0," Journal of Sensor and Actuator Networks, Vol. 1, No. 3, pp. 217-253.

Tan, L.; Wang N. (2010), "Future internet: the internet of things," in Proceedings of the 3rd International Conference on Advanced Computer Theory and Engineering (ICACTE '10), Vol. 5, pp. V5376-V5380, Aug 2010.

Terada, M. (2009), "Application of zigbee sensor network to data acquisition and monitoring," Measurement Science Review, Vol. 9, No.,6, pp.,183-186.

Tsai, C. W. et al. (2014), "Future internet of things: open issues and challenges", Wireless Networks, Vol. 20, No. 8, pp. 2201-2217.

Tsai, Y. S. (2009), "The Issues to Think about Before Entering the Cloud Services Market," http://www.zdnet.com.tw (Accessed on 2009).

Vermesan, O. et al. (2011), "Internet of things strategic research roadmap, in Internet of Things: Global Technological and Societal Trends", Vol. 1, pp. 9-52. 
D Brazilian Journal of Operations \& Production Management

Volume 14, Número 4, 2017, pp. 567-576

DOI: 10.14488/BJOPM.2017.v14.n4.a12
Wan, J. et al. (2014), "Context aware vehicular cyber-physical systems with cloud support: architecture, challenges, and solutions", IEEE Communications Magazine, Vol. 52, No. 8, pp. 106-113.

Wang, H. (2014), "Constructing the Green Campus within the Internet of Things Architecture", Hindawi Publishing Corporation, International Journal of Distributed Sensor Networks, Vol. 2014, Article ID 804627, 8 pp.

Wang, S. et al. (2016), "Implementing Smart Factory of Industrie 4.0: An Outlook", Hindawi Publishing Corporation, International Journal of Distributed Sensor Networks, Vol. 2016, Article ID 3159805, 10 pp.

Want, R. (2006), “An introduction to RFID technology", IEEE Pervasive Computing, Vol. 5, No. 1, pp. 25-33.

Wu, M. et al. (2010), "Research on the architecture of internet of things," in Proceedings of the 3rdlnternationalConferenceonAdvancedComputerTheoryand Engineering (ICACTE'10), Vol. 5, pp. V5-484-V5-487, IEEE, Chengdu, China, Aug. 2010.
Yang, C. S. et al. (2013), "The effect of green supply chain management on green performance and firm competitiveness in the context of container shipping in Taiwan". Transp. Res. Part E: Logistics and Transportation Review 55, pp. 55-73.

Zhu, X. et al. (2012), "A review of RFID technology and its managerial applications in different industries", Journal of Engineering and Technology Management, Vol. 29, No. 1, pp. 152-167.

ZigBee Alliance (2007a), "The Choice for Energy Management and Efficiency", ZigBee White Paper, http://www.zigbee.org/Products/TechnicalDocumentsDownload/tabid/237/ Default.aspx (Accessed on August 2007).

ZigBee Alliance (2007b), "ZigBee Home Automation Public Application Profile", http://www.zigbee.org/Products/TechnicalDocumentsDownload/tabid/237/Default.aspx (Accessed on August 2007). 